\title{
Doctor-Patient Communication to Improve Adherence to Anti- Hypertensive Treatment
}

\author{
Amin $\mathrm{ZA}^{1^{*}}$, Kabir $\mathrm{MI}^{2}$, Karami $\mathrm{JH}^{3}$, Nahar $\mathrm{N}^{4}$ \\ ${ }^{I}$ Department of Health Economics, Armed Forces Medical Institute, Dhaka Cantonment, Dhaka, \\ Bangladesh; ${ }^{2}$ Department of Epidemiology, National Institute of Preventive and Social Medicine, Dhaka, \\ Bangladesh; ${ }^{3}$ Department of Statistics, University of Dhaka, Dhaka, Bangladesh; ${ }^{4}$ Ma-Moni MNCSP Save \\ the Children, Dhaka, Bangladesh
}

\begin{abstract}
Background: Non-adherence to medication increases patient's risk of morbidity, mortality and economic wastage of scare medical resources. This study was conducted to assess the role of doctor-patient communication and duration of consultation, as tools to improve adherence to hypertension treatment.

Methods: Data of this cross-sectional study were collected by face to face interview and document review at Combined Military Hospital (CMH), Dhaka among 253 conveniently recruited hypertensive patients attending outpatient department during July 2016 to June 2017. Mean-age of the respondents was 49.2 $( \pm 10.4)$ years, mostly married male $(54.9 \%$ male, $95.3 \%$ married $)$. Mean consultation duration experienced by the respondents was $5.3( \pm 1.3)$ minutes. Among the participants, $63.64 \%$ experienced effective communication, $66 \%$ were adherent and $34 \%$ were non-adherent to medication. Among the respondents with effective communication, $92.5 \%$ were adherent to medication. On the contrary, among the respondents with ineffective communication, $80.4 \%$ were non-adherent.

Results: Duration of consultation had significant association with adherence to hypertension treatment $(p<0.001)$. Association between communication and adherence to medication was highly significant $(p<0.001)$. Binary logistic regression revealed that respondents were 3.23 times more adherent to medication with favorable response to the item- 'Doctor gave me as much information as I wanted' ( $p=0.041$ ); and 10.24 times with favorable response to the item- 'Doctor checked to be sure that I understood everything' $(p=0.006)$. Patients' faithfulness in carrying out prescription and proscriptions correctly, depends on the adequacy and accuracy of patient's knowledge of what they were supposed to do and on their motivation.

Conclusion: Thus, it is necessary to formulate interventions to scale up communication skill of the physicians, and devise effective ways to educate patients on medication of chronic diseases. Further studies on characteristics of consultation to make it motivating and more effective may be conducted.
\end{abstract}

Keywords: Treatment adherence, Medication compliance, Doctor-patient communication

\section{Introduction}

Hypertension is a condition with a tremendous economic and public health impact which contributes to disability, increase health care costs and mortality. It affects up to $37 \%$ of global adult population and is estimated that 7.1 million deaths are due to hypertension. ${ }^{2}$ Although the management and control of hypertension reduces morbidity and mortality, paradoxically the percentage of patients with

*Correspondence: Zulfiquer Ahmed Amin, Department of Health Economics and Hospital Management, Armed Forces Medical Institute, Dhaka Cantonment, Dhaka, Bangladesh; e-mail: zulfiquer732@yahoo.com

ORCID: https://orcid.org/0000-0003-1183-5647 controlled hypertension has been reported to vary between $5.4 \%$ and $58 \%$ only worldwide. ${ }^{3}$

One of the major causes of this global hypertension threat is failure to take medication as advised. Poor adherence attenuates optimum clinical benefits and therefore reduces the overall effectiveness of health systems. In developing countries, when taken together with poor access to health care, lack of appropriate diagnosis and limited access to medicines, poor adherence is threatening to render futile any effort to tackle chronic conditions, such as diabetes, depression, hypertension, TB and HIV/AIDS. ${ }^{2}$ 
It is axiomatic that effective care of patients requires both technical expertise - that is diagnosis and treatment, and interpersonal or psychosocial skill. The latter comprise the physician-patient relationship, patient education, counseling and the caring function. The psychosocial components are particularly important in the outdoor management of patients with chronic diseases, because effectiveness of treatment for conditions like hypertension, diabetes mellitus and heart diseases depends largely on patients faithfulness in carrying out instructions correctly. ${ }^{4}$ Nikita Sabherwal et al in Delhi, India, found $62 \%$ of the patients had experienced ineffective communication by the doctor. ${ }^{5}$ Various study findings clearly emphasize its abysmal lack in practice and the over-reaching need for the doctors to establish effective communication with the patients. Findings across 106 studies in a meta-analysis by HaskardZolnierek $\mathrm{K}$ et al the association between physician communication and patient adherence is positive and significant $(p<.001){ }^{6}$

The WHO defines adherence as "the extent to which the persons behavior (Including medicationtaking) corresponds with agreed recommendations from a healthcare provider". 7 It includes the initiation of the treatment, implementation of the prescribed regime, and discontinuation of the pharmacotherapy. It is noted that the adherence rate of less than $75 \%$ with short-acting antihypertensive drugs increase the risk of cardiovascular complications. ${ }^{8}$ Donald E Morisky et al in a study found $32.1 \%$ low adherers, $52.0 \%$ medium adherers, and only $15.9 \%$ high adherers. ${ }^{9}$

Except a qualitative study on communication skill of intern-doctors by Rahman A, no other study could be found in the context of Bangladesh; exposing a gap in knowledge of communication skill of service providers in Bangladesh. ${ }^{10}$ There are a number of factors that predict patient adherence to treatment, but only the relationship between doctor-patient communication and adherence to treatment has been focused in this study. The objective of this study was to determine the link between doctor-patient communication, and adherence to anti-hypertensive treatment. Thus, this study will help to identify weaknesses and strengths in communication skills of the physicians with the patient, its relation to adherence to treatment, and potential areas for further improvement.

\section{Materials and Methods}

This cross-sectional study was conducted at Combined Military Hospital, Dhaka among 253 conveniently recruited hypertensive patients, attending outpatient department during July 2016 to June 2017. The data were collected by face to face interview and document review. Study involved quantitative method of data collection with component of qualitative data collection. Assuming proportion of patient's adherence to treatment for chronic condition as $p(0.15), 5 \%$ margin of error (d) and confidence level of $95 \%$ $\left(\mathrm{z}^{\infty / 2}=1.96\right)$, the minimum sample size was $196{ }^{7}$ Finally, a sample of 253 was recruited. 'Interview' of all the respondents was conducted to identify the contributing factors for skipping prescriptions and proscriptions. Participants, who were diagnosed as case of hypertension at least six months before recruitment into the study, receiving antihypertensive treatment, age 18 years or above and willing to participate were recruited.

Physicians involved in treating and communicating with patients were military doctors with specialization in internal medicine and/or cardiology. Communication skill of the clinicians, as perceived by the respondents was determined by using 'Communication Assessment Tool' (CAT). ${ }^{11}$ The CAT with 15 items, asked the respondents to rate different dimensions of communication and interpersonal skills of the physician using a 5-point Likert Scale (1=Poor, 2=Fair, 3=Good, 4=Very good, 5= Excellent). The first 14 questions focused specifically on the physician's interpersonal and communication skills. The last question concerned about patient interaction with the staffs. The 'Cronbach's Alpha' for the original CAT was 0.98. Any score above 3 was considered as 'Effective' and below 3, as 'Ineffective' communication. ${ }^{11}$ Higher score signified better communication.

The 8-item, 'Morisky's Medication Adherence Scale (MMAS-8)' was administered to the respondents to determine the self-reported adherence level to antihypertensive medication (Cronbach's Alpha=0.83). ${ }^{12}$ The first seven items were 'Yes/No' responses, while the last item was a 5-point Likert response. Every 'negative' response of the first 7 items scored 'one' 
and every positive response scored 'zero' (Except question no-6, for which the scoring was reverse). For question no-8, score obtained from 0 to 4 in Likert scale was divided by 4 to get a score out of value of one. Finally, all scores are summed up to get a total score out of eight. Higher scores indicated better adherence. Any score equal and above six was classified as adherent and below six as non-adherent respectively. $^{12}$ Data were analysed using SPSS. Descriptive statistics, and inferential statistics, like ttest, One way ANOVA, Chi Square test and binary logistic regression were performed. Level of significance for this study was chosen 5\%. Research protocol was approved by Ethical Review Board (Directorate General Medical Services, Bangladesh Armed Forces). Participation in the study was on voluntary basis. Privacy and confidentiality of data were strictly maintained.

\section{Results}

In this study, mean-age of the participants was $49.2( \pm 10.4)$ years, majority were male $(54.9 \%)$, belonged to age category $41-50$ years $(30.8 \%)$, $95.3 \%$ married, $44.3 \%$ were house wife, $30.8 \%$ had higher secondary qualification and $39.1 \%$ had family income within range of Tk 25,001 to 50,000 (table I).

Table I: Demographic characteristics of study sample $(n=253)$

\begin{tabular}{|c|c|c|}
\hline Variables & Variable characteristics & Frequency (\%) \\
\hline \multirow{2}{*}{ Sex } & Male & $139(54.9)$ \\
\hline & Female & $114(45.1)$ \\
\hline \multirow{5}{*}{ Age (Years) } & $31-40$ & $70(27.7)$ \\
\hline & $41-50$ & $78(30.8)$ \\
\hline & $51-60$ & $61(24.1)$ \\
\hline & More than 60 & $44(17.4)$ \\
\hline & Mean \pm SD & $49.15( \pm 10.375)$ \\
\hline \multirow{3}{*}{ Marital Status } & Married & $241(95.3)$ \\
\hline & Unmarried & $5(2.0)$ \\
\hline & Other & $7(2.8)$ \\
\hline \multirow{4}{*}{ Occupation } & Military & $27(10.7)$ \\
\hline & Retired Military & $80(31.6)$ \\
\hline & House Wife & $112(44.3)$ \\
\hline & Civil & $34(13.4)$ \\
\hline \multirow{8}{*}{ Education } & Illiterate & $4(1.6)$ \\
\hline & Primary & $17(6.7)$ \\
\hline & School Secondary & $74(209)$ \\
\hline & Course & $74(29.2)$ \\
\hline & Higher Secondary & $78(30.8)$ \\
\hline & Course & \\
\hline & Graduate & $43(17.0)$ \\
\hline & Post Graduate & $37(14.6)$ \\
\hline \multirow{6}{*}{$\begin{array}{l}\text { Family Income } \\
\text { (Taka) }\end{array}$} & $\leq 10,000 /-$ & $10(4.0)$ \\
\hline & $10001-25000 /-$ & $85(33.6)$ \\
\hline & $25001-50000 /-$ & $99(39.1)$ \\
\hline & $50001-100000 /-$ & $34(13.4)$ \\
\hline & $>100000 /-$ & $25(9.9)$ \\
\hline & Mean \pm SD & $43980.63 \pm 40130.72$ \\
\hline
\end{tabular}

Figure in parenthesis indicates row percentage
Mean consultation duration as expressed by the respondents was $5.34( \pm 1.31)$ minutes. More than half of the respondents $(57.3 \%)$ experienced a consultation duration between 3 minutes to 5 minutes. (figure 1)

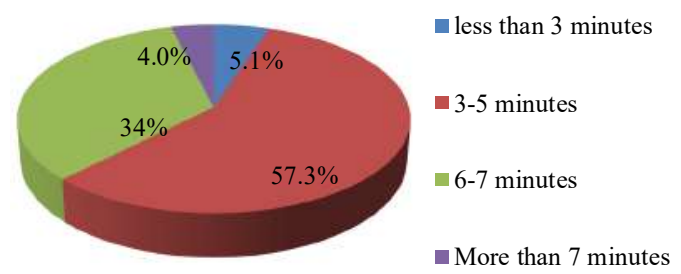

Figure 1: Duration of Consultation experienced by the study sample $(\mathrm{n}=253)$

In this study, using 'Communication Assessment Tool' (CAT), $63.6 \%$ and $36.4 \%$ of the patients were found to have experienced 'effective' and 'ineffective' communication respectively.

Relation of gender $(p<0.005)$, and occupation $(p<0.01)$ with communication was statistically significant (table II).

Table II: Association of demographic variables to level of DoctorPatient Communication $(\mathrm{n}=253)$

\begin{tabular}{|c|c|c|c|c|}
\hline \multirow{2}{*}{\multicolumn{2}{|c|}{ Variables }} & \multicolumn{2}{|c|}{ Communication $\mathrm{f}(\%)$} & \multirow{2}{*}{$p$ value* } \\
\hline & & Effective & Ineffective & \\
\hline \multirow{2}{*}{ Sex } & Male & $100(71.9)$ & $39(28.1)$ & \multirow{2}{*}{$<0.01$} \\
\hline & Female & $61(53.5)$ & $53(46.5)$ & \\
\hline \multirow{4}{*}{ Occupation } & Military & $22(81.5)$ & $5(18.5)$ & \multirow{4}{*}{$<0.01$} \\
\hline & Retired Military & $55(68.8)$ & $25(31.2)$ & \\
\hline & House wife & $59(52.7)$ & $53(40.7)$ & \\
\hline & Civil & $25(73.5)$ & $9(26.5)$ & \\
\hline
\end{tabular}

Figure in parenthesis indicates row percentage

* $p$ value is derived from $\chi^{2}$ test

There was a significant differences between groups (Categories of consultation duration) as determined by one-way ANOVA $(p=0.000)$. A Tukey post hoc test revealed that scores in communication skill were significantly higher for consultation duration category of more than 5 mints to 7 mints $(47.8 \pm 6.86$ mean 'communication skill score', $p<0.001)$ and more than 7 mints $(50.2 \pm 7.30$ mean communication skill score, $p<0.001$ ), compared to consultation duration category of more than 3 mints to 5 mints (40.8 \pm 6.6 mean 'communication skill score'). 
There was no statistically significant difference ( $p=0.45)$ between consultation duration category of 3 mints and below (37.9 \pm 7.7 mean 'communication skill score') and more than 3 mints to 5 mints $(40.8 \pm 6.6$ mean 'communication skill score'). (table III, IV and figure 2)
Table III: Association between categories of consultation-duration and mean 'score in communication skill' in one-way ANOVA $(n=253)$

\begin{tabular}{lccccc}
\hline & $\begin{array}{c}\text { Sum of } \\
\text { Squares }\end{array}$ & df & $\begin{array}{c}\text { Mean } \\
\text { Square }\end{array}$ & F & Sig. \\
\hline Between Groups & 3525.129 & 3 & 1175.043 & 25.540 & .000 \\
Within Groups & 11455.954 & 249 & 46.008 & & \\
Total & 14981.083 & 252 & & & \\
\hline
\end{tabular}

Table IV: Association between categories of consultation duration and mean 'score in communication skill' in Tukey's Post Hoc Test $(\mathrm{n}=253)$

\begin{tabular}{|c|c|c|c|c|c|}
\hline & $\begin{array}{c}\text { Independent Variable: } \\
\text { Consultation Duration (I) }\end{array}$ & $\begin{array}{c}\text { Categories of Consultation } \\
\text { Duration (J) }\end{array}$ & Mean Difference (I-J) & Std. Error & Sig. \\
\hline \multirow{12}{*}{ Tukey HSD } & & More than 3 mints to 5 mints & -2.90557 & 1.96376 & .451 \\
\hline & 3 mints and below & More than 5 mints to 7 mints & $-9.95385^{*}$ & 2.01998 & .000 \\
\hline & & More than 7 mints & $-12.35385^{*}$ & 2.85304 & .000 \\
\hline & & 3 mints and below & 2.90557 & 1.96376 & .451 \\
\hline & More than 3 mints to 5 mints & More than 5 mints to 7 mints & $-7.04828^{*}$ & .92659 & .000 \\
\hline & & More than 7 mints & $-9.44828^{*}$ & 2.21767 & .000 \\
\hline & \multirow{3}{*}{ More than 5 mints to 7 mints } & 3 mints and below & $9.95385^{*}$ & 2.01998 & .000 \\
\hline & & More than 3 mints to 5 mints & $7.04828^{*}$ & .92659 & .000 \\
\hline & & More than 7 mints & -2.40000 & 2.26761 & .715 \\
\hline & \multirow{3}{*}{ More than 7 mints } & 3 mints and below & $12.35385^{*}$ & 2.85304 & .000 \\
\hline & & More than 3 mints to 5 mints & $9.44828^{*}$ & 2.21767 & .000 \\
\hline & & More than 5 mints to 7 mints & 2.40000 & 2.26761 & .715 \\
\hline
\end{tabular}

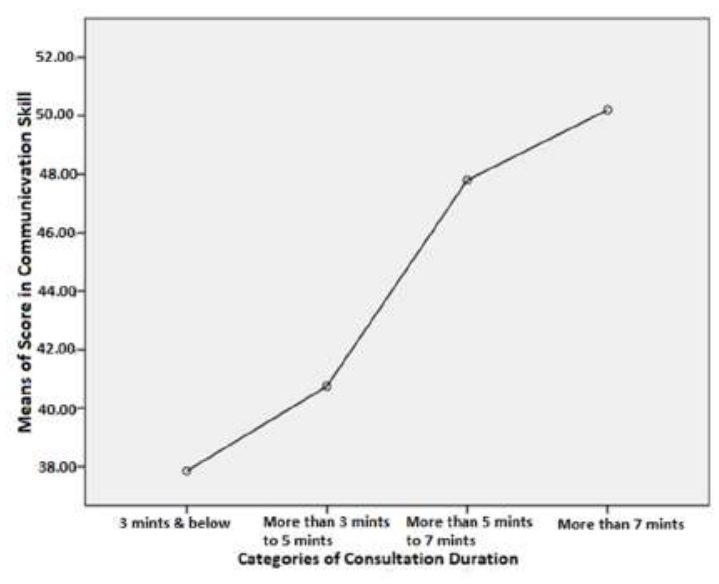

Figure 2: Mean Plot in ANOVA shows that with increase in duration of consultation, there are increases in score of communication skill as perceived by the respondents.

In this study, it was tried to explore the level of adherence for each CAT-item from patients' perspective. Binary logistic regression analysis revealed that respondents were 3.23 times more adherent to medication with favorable response to the item- 'Doctor gave me as much information as I wanted' ( $p=0.041)$; and 10.24 times more adherent with favorable response to the item'Doctor checked to be sure I understood everything' ( $p=0.006$ ) (table IV).

This study unfolded that $66 \%$ of the respondents were adherent to anti-hypertensive medication, rest $34 \%$ were non-adherent. Respondents who perceived effective communication were also more adherent to medication $(92.5 \%)$; whereas, the respondents who experienced ineffective communication, were comparatively less adherent to medication (19.6\%). Relation between communication and adherence to medication was found highly significant $(p<0.001)$. 
Table IV: Logistic Regression Analysis of item-wise score of Communication Assessment Tool (CAT) (n=253)

\begin{tabular}{|c|c|c|c|c|c|c|c|}
\hline \multirow{2}{*}{ Items in CAT } & \multirow{2}{*}{ B } & \multirow{2}{*}{ SE (B) } & \multirow{2}{*}{ Wald } & \multirow{2}{*}{$p$} & \multirow{2}{*}{ OR } & \multicolumn{2}{|c|}{ 95\% CI for OR } \\
\hline & & & & & & Lower & Upper \\
\hline Greeted me in a way that made me feel comfortable & 1.15 & .72 & 2.55 & .11 & 3.16 & .77 & 12.97 \\
\hline Treated me with respect & 1.01 & .67 & 2.24 & .14 & 2.74 & .73 & 10.22 \\
\hline Showed interest in my ideas about my health & .91 & .70 & 1.69 & .19 & 2.47 & .63 & 9.68 \\
\hline Understood my main health concerns & .40 & .64 & .39 & .53 & 1.49 & .43 & 5.22 \\
\hline Paid attention to me (Looked at me, listened carefully) & .49 & .67 & .54 & .46 & 1.63 & .44 & 6.06 \\
\hline Let me talk without interruptions & .03 & .73 & .002 & .97 & 1.03 & .25 & 4.34 \\
\hline Gave me as much information as I wanted & 1.17 & .60 & 3.77 & $.041 *$ & 3.23 & 1.19 & 10.55 \\
\hline Talked in terms I could understand & -.48 & .68 & .50 & .48 & .62 & .16 & 2.35 \\
\hline Checked to be sure I understood everything & 2.33 & .85 & 7.46 & $.006^{*}$ & 10.24 & 1.93 & 54.31 \\
\hline Encouraged me to ask questions & -.60 & .82 & .54 & .46 & .55 & .11 & 2.71 \\
\hline Involved me in decision making as much as I wanted & -1.27 & .84 & 2.27 & .13 & .28 & .05 & 1.47 \\
\hline Discussed next step, including any follow-up plans & .61 & .96 & .41 & .52 & 1.84 & .28 & 11.98 \\
\hline Showed care and concern & .24 & .79 & .09 & .76 & 1.27 & .27 & 5.99 \\
\hline Spent the right amount of time with me & .69 & .75 & .84 & .36 & 1.99 & .46 & 8.64 \\
\hline Staffs treated me with respect & -.92 & .56 & 2.66 & .10 & .40 & .13 & 1.20 \\
\hline
\end{tabular}

$* p<.05$, Model Chi Square $=\left[\chi_{15}^{2}(\mathrm{n}=253)=203.65 ; p<0.001\right]$, Nagelkerke $\mathrm{R}^{2}=0.77$

Table V: Parameter Estimates in Binary Logistic Regression contrasting Non-Adherent group versus groups of other variables those were found significant in Chi Square test $(\mathrm{n}=253)$

\begin{tabular}{|c|c|c|c|c|c|c|c|}
\hline \multirow{2}{*}{ Variable } & \multirow{2}{*}{ B } & \multirow{2}{*}{ SE (B) } & \multirow{2}{*}{ Wald } & \multirow{2}{*}{$p$} & \multirow{2}{*}{ OR } & \multicolumn{2}{|c|}{$95 \% \mathrm{CI}$ for OR } \\
\hline & & & & & & Lower & Upper \\
\hline Occupation & & & 2.075 & 0.56 & & & \\
\hline *Effective Communication & 3.74 & .73 & 26.24 & $<0.001$ & 42.09 & 10.06 & 176.04 \\
\hline$* *$ Gender & -2.17 & 2.18 & .98 & 0.73 & .12 & .002 & 8.26 \\
\hline$* * *$ Consultation Duration & & & 8.20 & .042 & & & \\
\hline 3-5 minutes & 1.34 & 1.03 & 1.70 & .044 & 3.82 & .51 & 28.54 \\
\hline 6-7 minutes & 2.57 & 1.22 & 4.43 & .035 & 13.06 & 1.19 & 143.12 \\
\hline More than 7 minutes & 2.63 & 1.24 & 4.52 & .033 & 13.9 & 1.21 & 149.31 \\
\hline$* * * *$ Education & & & 7.96 & .039 & & & \\
\hline Primary & .72 & .94 & 1.45 & .043 & 2.05 & .44 & 24.21 \\
\hline $\mathrm{SSC}$ & 1.03 & .96 & 1.61 & .037 & 2.80 & .49 & 28.33 \\
\hline HSC & 1.09 & .98 & 1.68 & .044 & 2.98 & .53 & 29.44 \\
\hline Graduate & 1.22 & 1.02 & 1.72 & .041 & 3.4 & 1.21 & 34.11 \\
\hline
\end{tabular}

* Ineffective Communication is the reference

** Female is reference

*** Consultation less than 3 minutes duration is the reference

**** Illiterate is the reference

Model Chi Square $=\left[\chi^{2}(1, \mathrm{n}=253)=239.58, p<0.001\right]$, Nagelkerke $\mathrm{R}^{2}=0.85$

\section{Discussion}

Using Communication Assessment Tool (CAT), this study found that respondents experienced $63.64 \%$ 'effective' and $36.36 \%$ 'ineffective' communication between doctor and patient. This study differs from the findings of Nikita Sabherwal, ${ }^{5}$ conducted in Delhi, India, where $62 \%$ of the patients said that they had experienced ineffective communication by the doctor, while only $38 \%$ of the patients agreed that they had effective communication during their interaction with the physicians. This might have resulted from the differences in use of research instruments to assess the communication skill and the differences in average duration of consultation by the physicians in two facilities (In present study 5.34 $( \pm 1.31)$ minutes, in comparison to $2.25( \pm 1.11)$ minutes in the reference study) with two different social settings.

In this study, out of 253 respondents, $66 \%$ were Adherent, and $34 \%$ were Non-Adherent to antihypertensive medication. The result is broadly consistent with the findings of AzinBehnood-Rod et al $(2016)^{13}$ where $66.1 \%$ of the respondents showed adherence and $33.9 \%$ showed nonadherence to anti-hypertensives. Hossian SZ et al in a study in Dhaka Medical College Hospital found $55.47 \%$ patients were adherent to anti- 
hypertensive treatment. ${ }^{14}$ This study suggests that rate of patient's adherence to anti-hypertensive medication in Dhaka CMH was relatively higher than other studies conducted in Bangladesh.

Mean consultation time as expressed by the respondents was $5.3( \pm 1.3)$ minutes. More than half of the respondents $(57.3 \%)$ experienced a consultation time with the physicians for 3 minutes to 5 minutes. Other studies found average consultation time with the physicians were 2.1 minutes, 2.5 minutes, in the context of Bangladesh. ${ }^{16-17}$ Consulting time varies greatly between countries. For example, in Great Britain, average consultation lengths for general practitioners are between 5 and 8 minutes, ${ }^{18}$ whereas in the United States and Sweden, they are 10 to 20 minutes or more. ${ }^{19}$

In this study, Communication Assessment Tool (CAT) items - 'Doctors Treat with Respect', 'Greeting and Feeling of Comfort', and 'Showing Care and Concern' scored means above 3(3.17 \pm $0.748,3.04 \pm 0.668,3.03 \pm 0.60$ respectively). Lowest mean- score $(2.55 \pm 0.638)$ was obtained in item- 'Staffs Treated with Respect'. This result indicated that an important source of gap in communication might be lack of support from the paramedics, and auxiliary staffs.

Binary Logistic Regression analysis revealed that respondents were 3.23 times more adherent to medication with favorable response to the item'Doctor gave me as much information as I wanted' $(p=0.041)$; and 10.24 times more adherent with favorable response to the item- 'Doctor checked to be sure I understood everything' $(p=0.006)$. This result indicated that more exchange of information between the doctor and the patient, and taking feedback by the doctor to reconfirm that messages exchanged were understood by the patient play important role in patients understanding, motivation and adherence to the treatment.

\section{Conclusion}

It can be inferred from the findings of this study, that adherence to medication among other factors, significantly depends on effective communication between the doctor and the patient. It is necessary to formulate interventions to scale up communication skill of the physicians, and devise effective ways of patient education on chronic diseases and medication. Further studies on communication skill of the clinicians, and characteristics of consultation that render any communication as effective should be conducted.

\section{Acknowledgement}

The authors gratefully acknowledge the partial funding by the Bangladesh Medical Research Council (BMRC). Authors also sincerely thank the participants of the study and authority of $\mathrm{CMH}$ Dhaka.

\section{Conflict in interest: None.}

\section{References}

1. Stein AD, Stoyanovsky V, Mincheva V, Dimitrov E, Hodjeva D, Petkov A et al. Prevalence, awareness, treatment and control of hypertension in a working Bulgarian population. Eur J Epidemiol. 2000; 16:265-70. DOI: 10.1023/A:1007601107752.

2. Ho PM, Rumsfeld JS. Beyond inpatient and outpatient care: alternative model for hypertension management. BMC Public Health. 2006; 19:6:257.

DOI: $10.1186 / 1471-2458-6-257$.

3. Trevisol DJ, Moreira LB, Kerkhoff A, Fuchs SC, Fuchs FD. Health-related quality of life and hypertension: a systematic review and metaanalysis of observational studies. J Hypertens. 2011;29:179-88.

DOI: 10.1097/HJH.0b013e328340d76f.

4. Inui TS, Yourtee EL, Williamson JW. Improved outcomes in hypertension after physician tutorial: A controlled trial. Ann Intern Med. 1976; 84: 646-51 DOI: doi.org/10.7326/0003-4819-84-6-646

5. Nikita S, Ashok M, Pandey NK, Ginny K, Paul K. A study of patient-physician communication and barriers in communication. International Journal of Research Foundation of Hospital \& Healthcare Administration. 2015; 3:71-78.

6. Haskard-Zolnierek K, Thompson TL. Health and Risk Communication [Internet]. [Place USA]: Oxford University Press USA; 2016 [Cited 2017 Aug 6].

7. Sabate E. Adherence to Long-Term Therapies: Evidence for Action. Geneva, Switzerland: World Health Organization; 2003.

8. Rasmussen JN, Chong A, Alter DA. Relationship between adherence to evidence-based pharmacotherapy and long-term mortality after acute myocardial infarction. JAMA. 2007;97: 177-86.

DOI: doi.org/10.1001/jama.297.2.177 
9. Morisky DE, Alfonso A, Krousel-Wood M, Harry J W. Predictive Validity of A Medication Adherence Measure in an Outpatient Setting. J Clin Hypertens (Greenwich). 2008 ;10:348-54.

DOI: doi.org/10.1111/j.1751-7176.2008. 07572.x

10. Rahman A. Initial assessment of communication skills of intern doctors in history-taking. Medical Teacher. 2000.22:184-88.

11. Makoul G, Krupat E, Chang CH. Measuring patient views of physician communication skills: Development and testing of the Communication Assessment Tool. Patient Educ Couns. 2007; 67:333-42.

DOI: doi.org/10.1016/j.pec.2007.05.005

12. Morisky D E, Alfonso A, Marie KW, Harry JW. Predictive Validity of a Medication Adherence Measure in an Outpatient setting. J Clin Hypertens 2008;10:348-54.

DOI: doi.org/10.1111/j.1751-7176.2008. 07572.x

13. Behnood-Rod A,Rabbanifar O,PourzargarP,Rai A,SaadatZ,Saadat $H$ et al. Adherence to Antihypertensive Medications in Iranian Patients. Int J Hypertens. 2016;2016: 7.

DOI: doi.org/10.1155/2016/1508752

14. Hossain SZ, Islam MR, Biswas $\mathrm{S}$ et al. Pattern of compliance to anti-hypertensive medications in hypertensive patients in a tertiary care hospital. J Dhaka Med Coll. 2015; 24:62-66.

DOI: doi.org/10.3329/jdmc.v24i1.29566

15. Turner BJ, Hollenbeak C, Weiner MG, Ten Have T, Roberts C. Barriers to adherence and hypertension control in a racially diverse representative sample of elderly primary care patients. Pharmacoepidemiol Drug Saf. 2009; 18:672-81.

DOI: doi.org/10.1002/pds. 1766

16. Hoque MSA. Study on outpatient systems analysis in military hospitals of Bangladesh. BAMJ. 1991;15:27-31.

17. Alam MM, Parveen F, Iqbal MJU, Noor N, Begum SA. Assessing patient care indicators in a tertiary care teaching hospital in Bangladesh. Bangladesh Medical Journal 2012; 41:21-24.

DOI: doi.org/10.3329/bmj.v41i1.18776

18. Groenewegen PP, Hutten JBF. Workload and job satisfaction among general practitioners: a review of the literature. Soc Sci Med. 1991; 32:1111-9.

DOI: doi.org/10.1016/0277-9536(91) 90087-S

19. Camasso MJ, Camasso AE. Practitioner productivity and the product content of medical care in publicly supported health centers. Soc Sci Med. 1994;38:733-48.

DOI: doi.org/10.1016/0277-9536(94)90464-2 